\title{
Modeling on the Aspects of Thermal Response of Bay of Bengal to Tropical Cyclone TC05B 1999 using Princeton Ocean Model (POM): Preliminary Results
}

\author{
Yashvant Das ${ }^{1,2, *}$, U. C. Mohanty ${ }^{1,3}$, Jain Indu ${ }^{1}$, M. Subba Rao ${ }^{4}$, A.S.N. Murty ${ }^{5}$ \\ ${ }^{1}$ CAS, Indian Institute of Technology, Hauz Khas, New Delhi, India \\ ${ }^{2}$ Research and Modelling Division, AIR Worldwide India Private Limited, Rockdale, Somajiguda, Hyderabad, India \\ ${ }^{3}$ EOCS, Indian Institute of Technology, Bhubaneshwar, India \\ ${ }^{4}$ CEA\&WMT, Jawaharlal Nehru Technological University, Kukatpally, Hyderabad, India \\ ${ }^{5}$ Department of Marine Sciences, Berhampur University, Berhampur, India \\ *Corresponding author: yashvantdas@rediffmail.com
}

Received March 04, 2014; Revised April 03, 2014; Accepted April 10, 2014

\begin{abstract}
Tropical cyclones (TC's), while moving over the ocean bring about significant changes in ocean thermal structure and other ocean environment. These oceanic thermal responses provide vital information for understanding the air-sea interaction processes. This study used Princeton Ocean Model (POM) to investigate the changes in the oceanic thermal characteristics of Bay of Bengal (BOB) associated with TC05B (Orissa super cyclone) 1999. Model was forced with the wind and heat plus salinity fluxes as surface forcing in different experiments. In order to provide reasonable and realistic cyclonic winds to the model as forcing, the tropical cyclone wind model (TCWM) was developed to generate the synthetic cyclonic winds and superimposed with the analyzed blended QSCAT/NCEP wind field. Results show significant drop in sea surface temperature (SST) beneath the storm centre and to the right of the track confirming the earlier findings and are in qualitative agreement with the available Tropical Rainfall Measuring Mission (TRMM) Microwave Imager (TMI) satellite SST imageries. Subsurface thermal structures also reflect significant impact of cyclonic vortex over BOB.
\end{abstract}

Keywords: tropical cyclone, synthetic vortex, sea surface temperature (SST) cooling, thermal structure

Cite This Article: Yashvant Das, U. C. Mohanty, Jain Indu, M. Subba Rao, and A.S.N. Murty, "Modeling on the Aspects of Thermal Response of Bay of Bengal to Tropical Cyclone TC05B 1999 using Princeton Ocean Model (POM): Preliminary Results.” American Journal of Modeling and Optimization, vol. 2, no. 2 (2014): 47-59. doi: 10.12691/ajmo-2-2-2.

\section{Introduction}

Strong atmospheric forcing events such as tropical cyclones (TCs) and the mutual response of atmosphere and ocean represent an extreme case of air-sea interaction process (Liu et al., 2012) and is critical for understanding the development and life cycles of the storms, which can improve storm intensity and track forecasting (Morey et al., 2006). The primary energy source driving these storms is the latent heat release due to the condensation of water vapour, which ultimately comes from the ocean (Jacob and Shay, 2003).The evolution, intensification and passage of TC's over tropical Indian Ocean regions (the Bay of Bengal and the Arabian sea) during pre- and postmonsoon periods is a common phenomena. The frequency of occurrence of TC in BOB is relatively higher during post-monsoon periods, however, there is a marked seasonal variations in their places of genesis, tracks and intensities (Anonymous, 1979; Mohanty et al., 2004). BOB's share comes out to be $5-6 \%$ of the total world ocean waters (Gray, 1979).
TCs are strongly-coupled to ocean mixed layer and surface waves through momentum, heat and moisture exchanges at the air-sea interface (Liu et al., 2012).TC generated strong winds produce intense mixing and divergent flows in the upper layers of the ocean. This results in redistribution of waters through (entrainment and upwelling from depths below) oceanic vertical mixing resulting in SST reduction and corresponding reduction of sea surface fluxes (Maeda, 1964; Gopalakrishna et al., 1993; Jacob and Shay, 2003).

Oceanic response to TCs has been studied theoretically and through applying the numerical modeling during past decades. Shay et al. (2000) investigated the upper- ocean response to the passage of Hurricane Gilbert (1988) using in situ observations and found that Hurricane Gilbert induced significant decreases in the sea surface temperature (SST) by as much as $3.5-4{ }^{\circ} \mathrm{C}$ and the maximum currents in mixed layer ranged from 1 to $1.4 \mathrm{~m}$. Using mooring data sets, Dickey et al. (1988) studied the upper ocean response to Hurricane Felix (1995). Their study revealed, important findings of the expected upperocean responses to hurricane including decrease in SST, strong inertial motion, large amplitude internal gravity 
waves in the thermocline, strong vertical turbulent mixing and heat exchange, and cooling of the upper mixed layer that persisted for several days (Liu et al., 2012). Through their studies they also explored the position of maximum cooling to be biased to the right of the path of hurricanes in keeping with earlier findings (Greatbatch, 1985; Cornillon et al., 1987). Zedler et al. (2002) extended the study of Dickey et al. (1988) by making more detailed analyses and using four different one-dimensional mixed layer models to simulate ocean responses. The results showed that one-dimensional model could partly simulate the responses to Hurricane Felix for both temperature and currents. SST may decrease by up to $6^{0} \mathrm{C}$ depending on the storm's intensity, spatial extent, and propagation speed, and the oceanic mixed layer thickness (Leipper, 1967; Wright, 1969; Price, 1981; Stramma et al., 1986; Nelson 1998; Shay, 1994; Wentz et al., 2000; Lin et al., 2003; Sadhuram, 2004).

Oceans response due to the passage of TC in the North Indian Ocean (BOB) has been reported by earlier studies (Gopalakrishana et al., 1993; Chinthalu et al., 2001; Subramanyam et. al., 2005). Their findings confirm that in the regions of weaker upper ocean stratification (southern and western BOB) magnitude of SST decreases due to the cyclone was $\sim 2^{0}$ C (Rao, 1987, Rao, 2002; Gopalkrishna et al., 1993) while in the Northern Bay, where the upper ocean stratification is strong due to the low salinity waters, the SST decrease was between $0.3^{0} \mathrm{C}$ and $0.9^{0} \mathrm{C}$
(Vinaychandran, 2002). Kara et al. (2002, 2003a, 2003b).On their model simulation reported the SST drop of $0.5^{0}$ to $0.8^{0} \mathrm{C}$ over the BOB during tropical cyclones 1999. Subramanyam et al. (2005) confirm the same findings. The BOB is one of the largest marginal sea of the Indian Ocean, extending across both tropical and subtropical zones and encompassing a surface area of $2.2 \times 10^{6} \mathrm{~km}^{2}$ (Figure 1). Studies on the thermal characteristics, circulations patterns and other aspects of the BOB have been studied and documented well. However, there is a sparse modeling study on the BOB's thermal response to super cyclonic winds. Thus BOB is chosen to investigate the oceanic response to TC05B 1999, using the Princeton Ocean Model (POM). The POM was forced with QSCAT/NCEP blended analysis wind fields and superimposed with the synthetically generated cyclonic winds (Tropical Cyclone Wind Model (TCWM) by Carr and Elsberry (1997)) of the same resolutions.

The outline of the paper is as follows. Introduction is given in section 1. Section 2 describes the movements of TC05B 1999 over the BOB (North Indian Ocean). Section 3 delineates the blended QSCAT/NCEP and TCWM generated synthetic wind data. Section 4 describes the POM model, study domain and time steps Section 5 depicts the experiment design. Section 6 describes the results of the numerical simulation and Section 7 gives the conclusions.

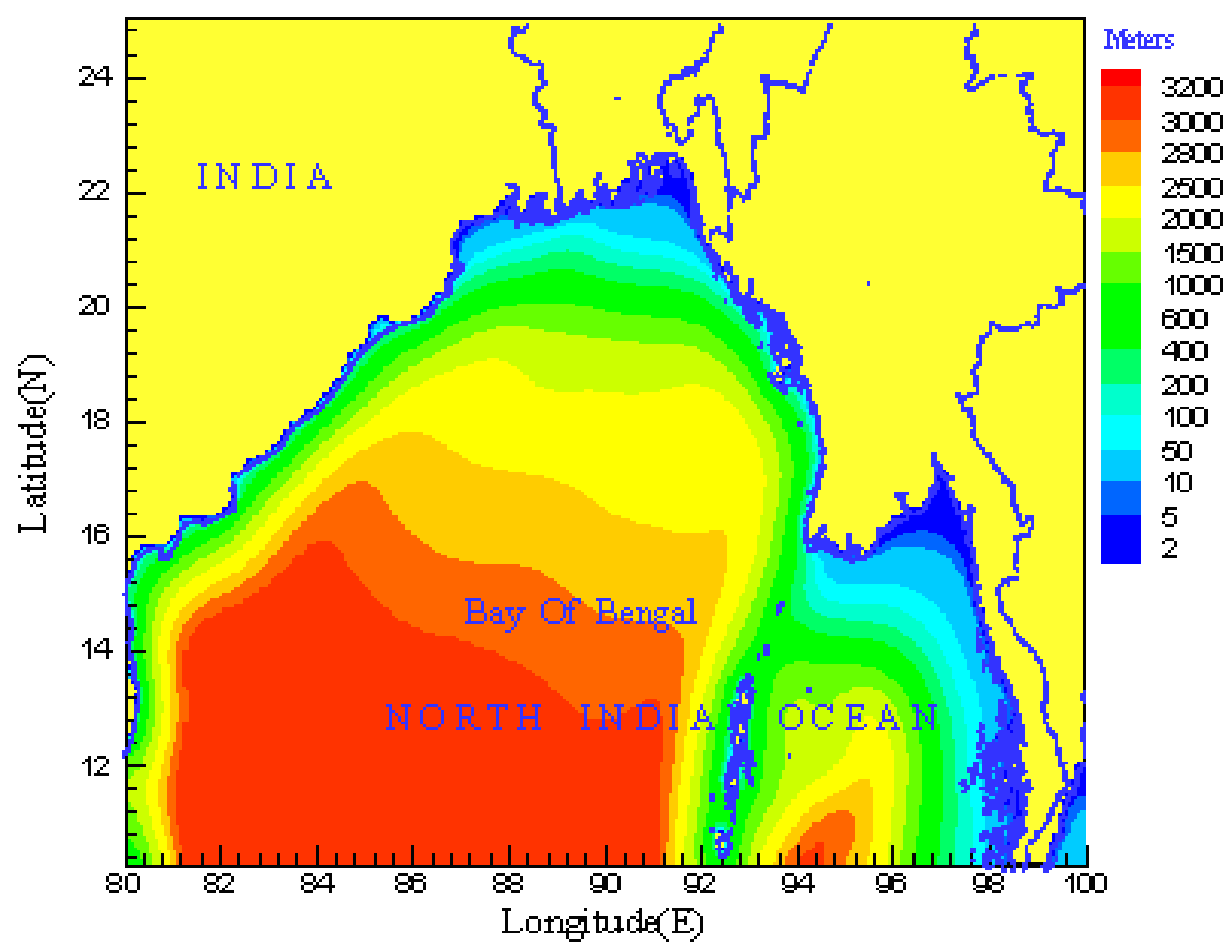

Figure 1. Map of the study domain representing the bathymetry (meters) with colour filled isopleths of Bay of Bengal (North Indian Ocean)

\section{Tropical Cyclone TC05B 1999}

The 1999 Orissa cyclone, also known as TC05B (Orissa Super Cyclone) 1999 and Paradip cyclone, was the deadliest north Indian Ocean tropical cyclones. The system has been chosen for wind field generation and to study the oceanic thermal response to TC05B, 1999. As an initiation of genesis a tropical depression formed over the Malay Peninsula on October 25. It moved to the northwest and became a tropical storm on October 26. It continued to strengthen into a cyclone on the $27^{\text {th }}$. On October 28 , it became a severe cyclone with a peak of $160 \mathrm{mph}(260 \mathrm{~km}$ $\mathrm{h}^{-1}$ ) winds. It hit India the next day (on 29 $9^{\text {th }}$ Oct 1999) as a $155 \mathrm{mph}$ (250 $\mathrm{km} \mathrm{h}^{-1}$ ) cyclone (IMD). On October 29, the cyclone hit the Indian state of Orissa near the city of Bhubaneshwar. The ridge to the north blocked further inland movement, and the cyclone stalled about 30 miles $(50 \mathrm{~km})$ inland of the ocean. It slowly weakened, 
maintaining tropical storm strength as it drifted southward. The cyclone re-emerged into the Bay of Bengal on October 31, and dissipated on November 3 over the open waters.

Orissa super cyclone was one of the most deadly tropical cyclones which originated in the Bay of Bengal and made landfall in the Orissa state of India causing a huge damage to life and property. During the life-cycle of about 9 days ( $25^{\text {th }}$ Oct $-3^{\text {rd }}$ Nov 1990) its fatality could be well imagined as it attained the status of super cyclonic storm with wind speeds more than $250 \mathrm{~km} \mathrm{~h}^{-1}$. Figure 2 shows the track of the TC05B 1999 (Japan Aerospace Exploration Agency Earth Observation Research Center) with their characteristics representing the date at 00UTC, chosen for wind field generation and to study the oceanic thermal response. The direction of movement is in the northwest direction in the BOB, Indian Ocean and after hitting the mainland recurving back to the ocean and dissipates under unfavorable ocean-atmospheric conditions.

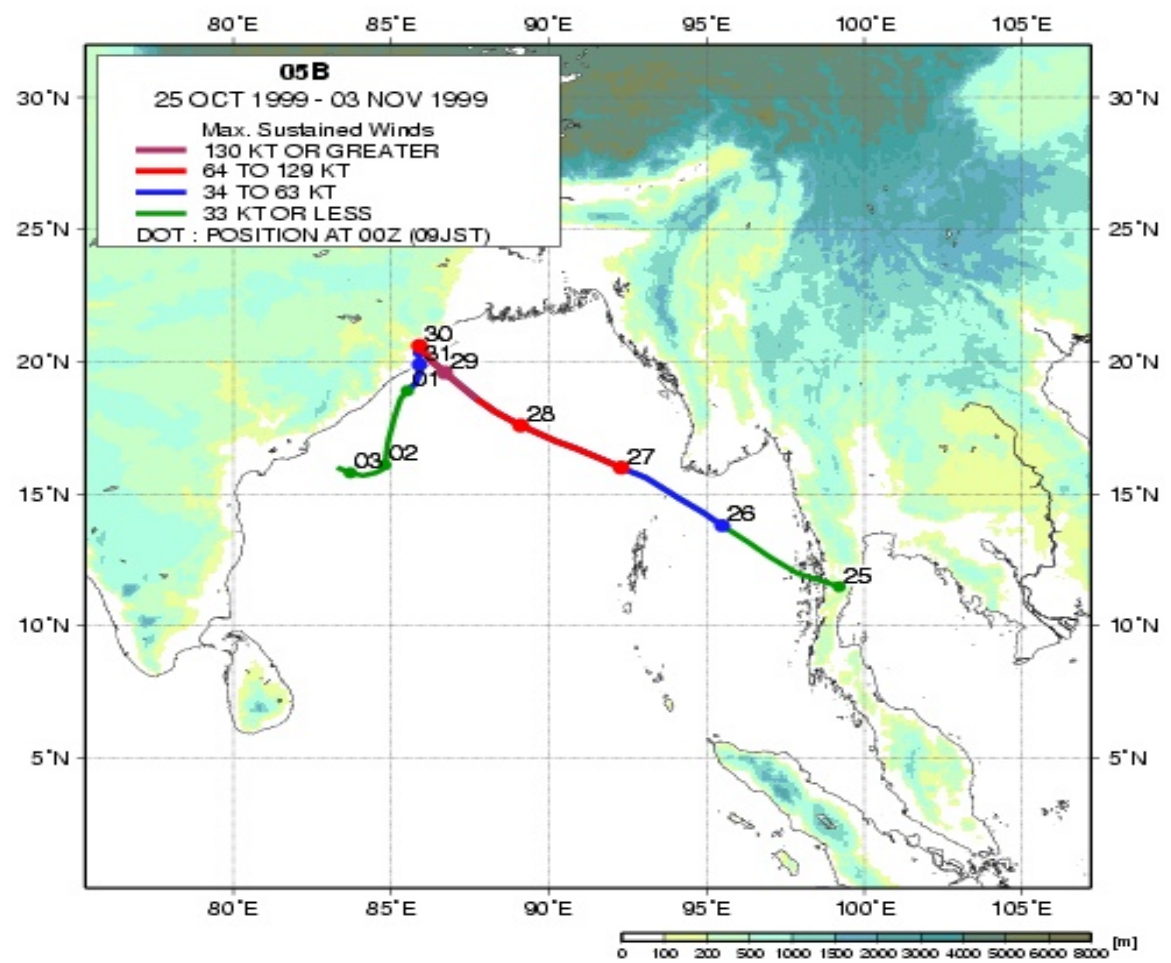

Figure 2. Track of the TC05B 1999 over Bay of Bengal (BOB) moving northwestwards with superscribed dates from $25^{\text {th }}$ Oct. to $3^{\text {rd }}$ Nov., 1999.Colours in the tracks are the indicative of the intensities with green as lower and red the higher

\section{Tropical Cyclonic Wind Model (TCWM)}

Tropical cyclone wind profile model developed by Carr and Elsberry, 1997 is based on the angular momentum balance to compute the wind vector relative to the center of the tropical cyclone. The synthetic cyclonic winds are generated by taking into account the cyclone parameters such as size $\left(R_{0}\right)$, distance from the center of the cyclone (r), maximum tangential velocity $\left(R_{m}\right)$, translational velocity $\left(\mathrm{V}_{\mathrm{t}}\right)$ and coriolis parameter (f) and this is considered as cyclonic wind input.

The model cyclone has tangential and radial wind components varying with the radial distance (r) given as follows:

$$
\begin{aligned}
& v_{c}(r)=\frac{f_{0}}{2}\left[R_{0}\left(\frac{R_{0}}{r}\right)^{X}-r\right] \frac{a^{4}}{1+a^{4}}, \\
& u_{c}(r)=\tan (\gamma) v_{c}(r),
\end{aligned}
$$

Where, $\gamma=$ inflow angle of the wind, $a=r / R_{m}$ (scaling factor), $\mathrm{x}=$ positive constant $<1$ and taken as $\mathrm{x}=0.4$, as proposed by Carr and Elsberry (1997). The superimposition of the synthetic wind field with real time
NSCAT wind data is done similar to Chu et al., 2000, as follows.

$$
V=(1-\varepsilon)\left(V_{c}+V_{t}\right)+\varepsilon V_{b g},
$$

where $\mathrm{V}_{\mathrm{bg}}=$ background wind field, $\mathrm{V}_{\mathrm{t}}=$ storm translational velocity, and ' $\varepsilon$ ' is computed by

$$
\varepsilon=\frac{c^{4}}{1+c^{4}}, \quad c=\frac{r}{0.9 R_{0}} .
$$

Where, the other symbols have their usual meanings.

The QSCAT/NCEP blended wind vectors (6-hourly) show that the storm was represented well, but in terms of magnitude and vortex structure (in some instances), it was not reflected (Scatterometer limitations) as the maximum intensity of TC05B, 1999 was about $70 \mathrm{~ms}^{-}{ }^{1}$. Hence, tropical cyclone model generated synthetic vortex $\left(25^{\text {th }}\right.$ Oct 1999 to $31^{\text {st }}$ Oct 1999, 6-hourly) are superimposed with QSCAT/NCEP blended winds and used in forcing the model as realistic cyclonic winds. Cubic spline interpolation technique is used to bring the superimposed wind data fields to match the resolution of model. The 6hourly evolutions of synthetic wind vectors generated using tropical cyclone model and QSCAT/NCEP blended surface wind vectors are shown in Figure 3a \& Figure $3 b$ for 00UTC $27^{\text {th }}$ Oct. 1999 to 18 UTC $29^{\text {th }}$ Oct. 1999. 
50

American Journal of Modeling and Optimization
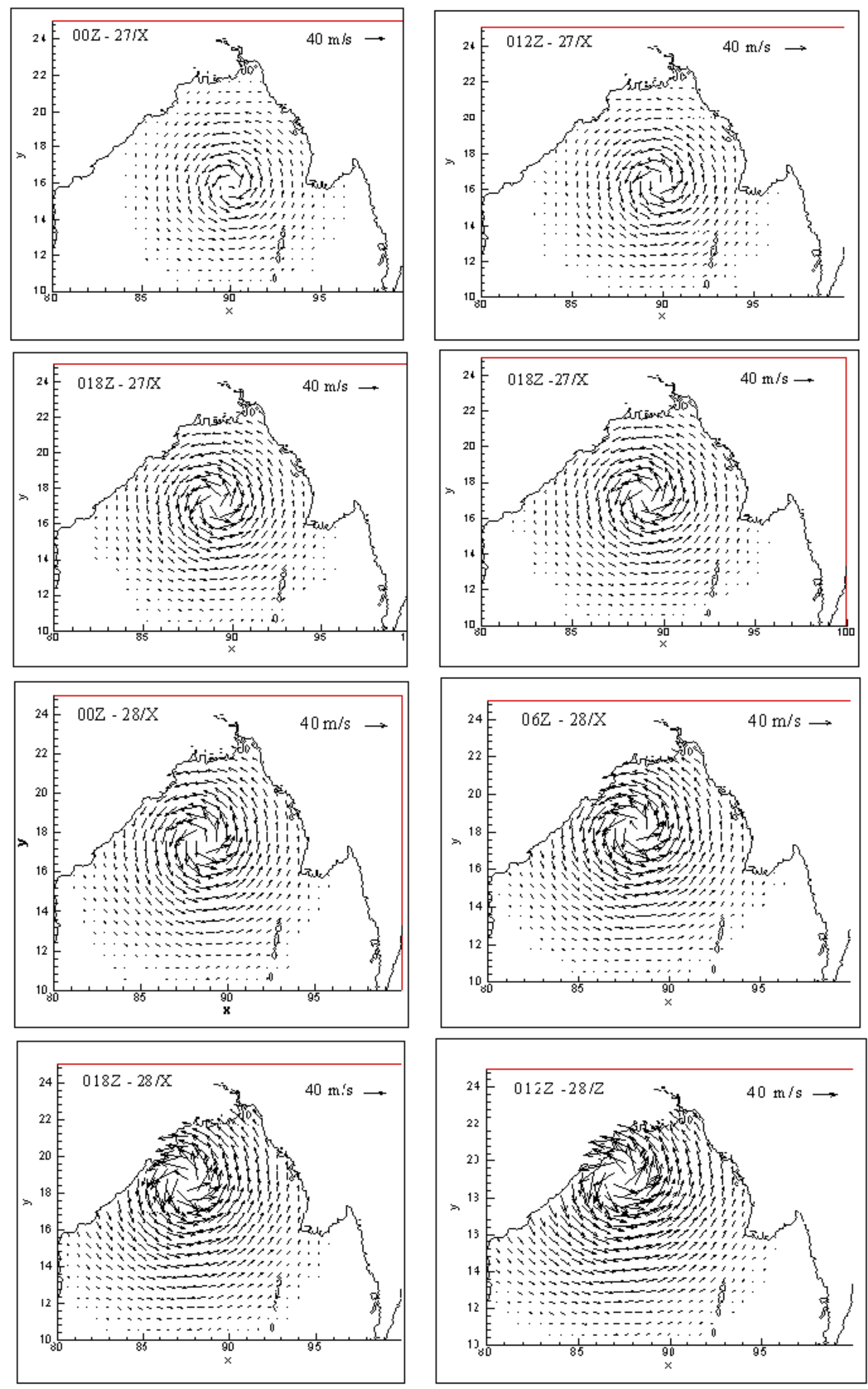

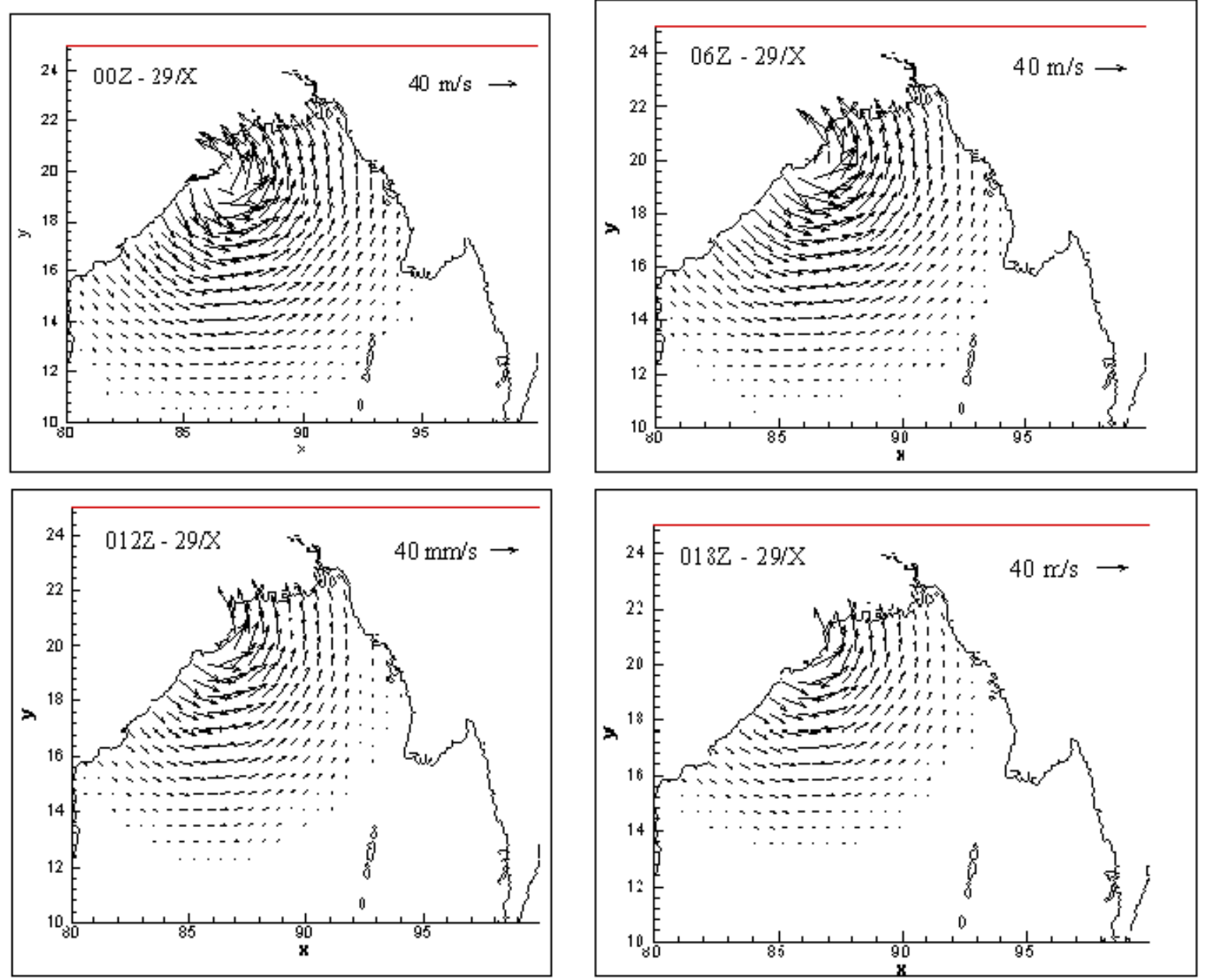

Figure 3. a. TCWM generated synthetic wind vectors 6-hourly (00UTC 27 to 00UTC 29 Oct., 1999) over study domain (BOB), x= Longitude (Deg.E) and $\mathrm{y}=$ Latitude (Deg.N)
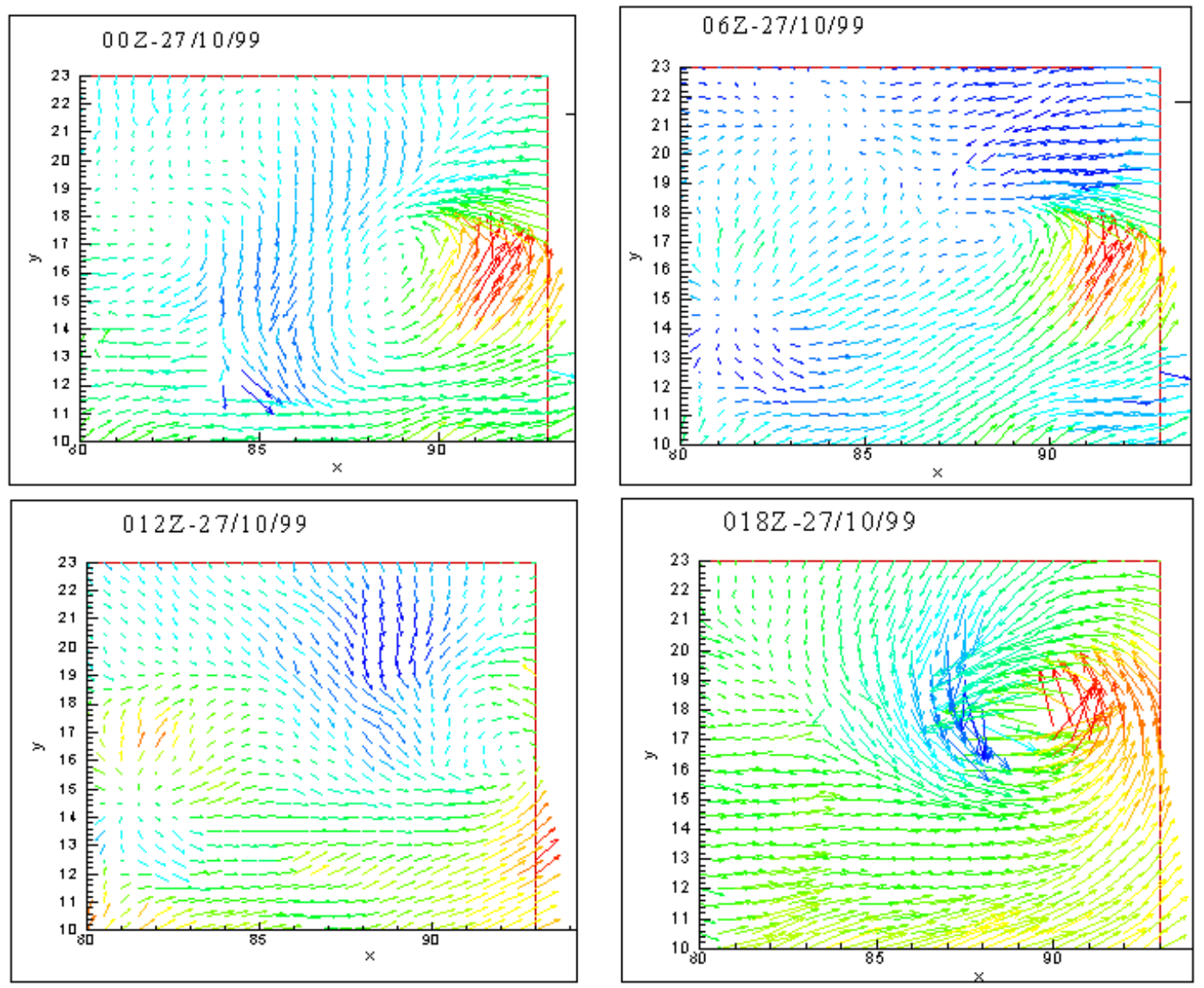

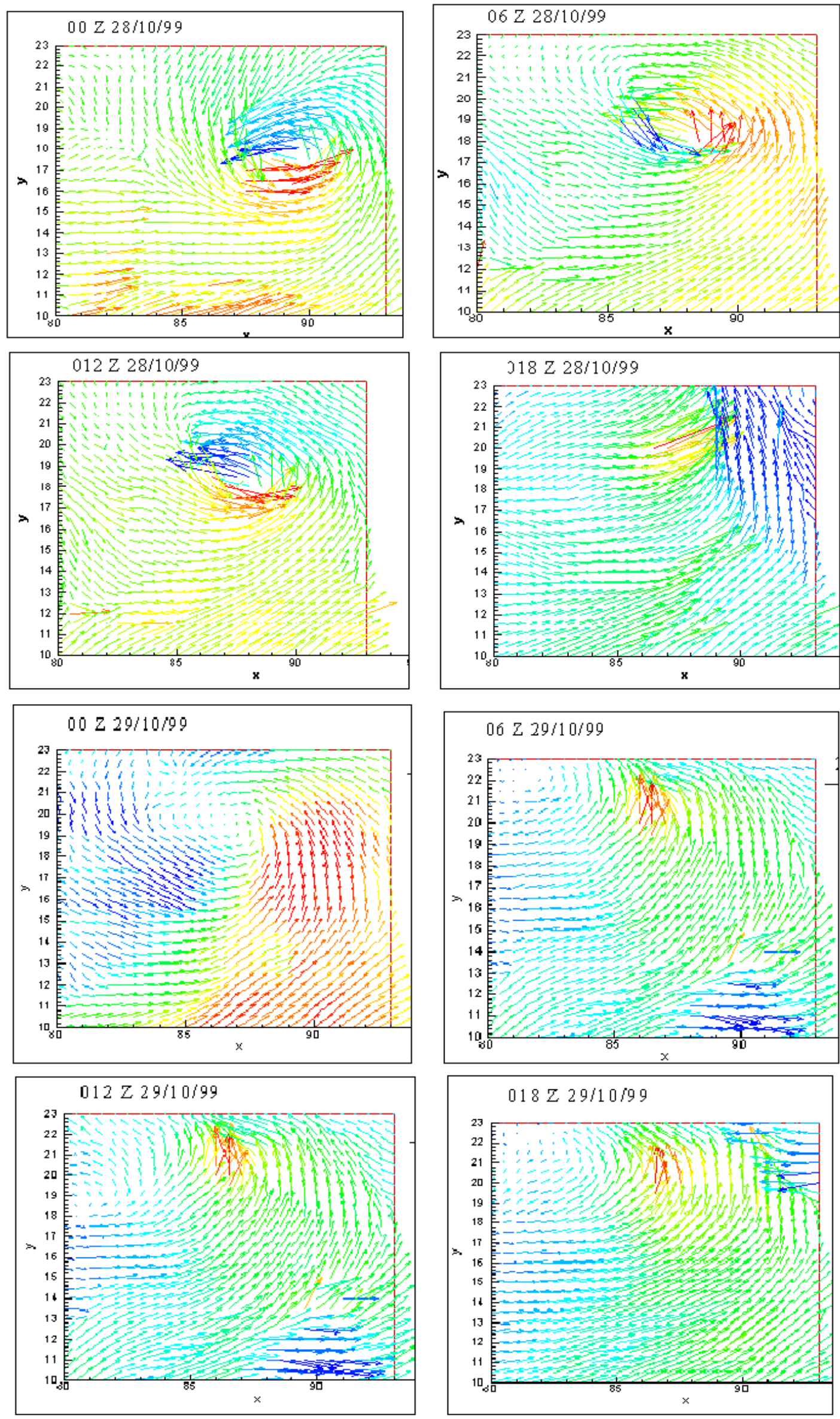

Figure 3. b. The QSCAT/NCEP blended wind vectors 6-hourly (00UTC 27 to 00UTC 29 Oct., 1999) over study domain (BOB), x= Longitude (Deg.E) and $\mathrm{y}=$ Latitude (Deg.N)

Wind vector scale: $\stackrel{25 \mathrm{~m} / \mathrm{s}}{\longrightarrow}$ 


\section{The Princeton Ocean Model (POM)}

\subsection{Model Description, Study Domain and Time Steps}

The POM is a time-dependent, primitive equation ocean model on a three-dimensional grid with complete thermohaline dynamics that includes realistic topography (terrain-following) and a free surface. It includes the $2^{\text {nd }}$ order turbulence scheme as a sub model to represent well the mixed layer dynamics (Mellor \& Yamada, 1982). Model attributes are given in Table 1. Basic equations that is the continuity, momentum conservation and temperature and salinity equations (Blumberg and Mellor (1987), Mellor, 2001) in cartesian coordinate system in simplified form can be represented as, continuity equations:

$$
\frac{\partial u}{\partial x}+\frac{\partial v}{\partial y}+\frac{\partial w}{\partial z}=0
$$

$\mathrm{x}$-momentum equation:

$$
\frac{d u}{d t}=-\frac{1}{\rho_{0}} \frac{\partial p}{\partial x}-f v+\frac{\partial}{\partial z}\left(A_{m v} \frac{\partial u}{\partial z}\right)+F_{X},
$$

$\mathrm{y}$-momentum equation:

$$
\frac{d v}{d t}=-\frac{1}{\rho_{o}} \frac{\partial p}{\partial y}-f u+\frac{\partial}{\partial z}\left(A_{m v} \frac{\partial v}{\partial z}\right)+F_{y},
$$

Z-momentum or hydrostatic equation:

$$
\frac{\partial p}{\partial z}=-\rho g
$$

temperature equation:

$$
\frac{d T}{d t}=\frac{\partial}{\partial \mathbf{z}}\left(A_{h v} \frac{\partial T}{\partial \mathbf{z}}\right)+F_{T},
$$

salinity equation:

$$
\frac{d S}{d t}=\frac{\partial}{\partial z}\left(A_{h v} \frac{\partial S}{\partial z}\right)+F_{S} .
$$

The terms $d(\cdot) / d t, F x, F y, F T$ and FS presented in the equations (2), (3), (5) and (6) represent the total derivative terms, these unresolved processes and in analogy to the molecular diffusion can be described as

$$
\begin{gathered}
F_{x}=\frac{\partial}{\partial x}\left[2 A_{m} \frac{\partial u}{\partial x}\right]+\frac{\partial}{\partial y}\left[A_{m}\left(\frac{\partial u}{\partial y}+\frac{\partial v}{\partial x}\right)\right], \\
F_{y}=\frac{\partial}{\partial y}\left[2 A_{m} \frac{\partial v}{\partial y}\right]+\frac{\partial}{\partial x}\left[A_{m}\left(\frac{\partial u}{\partial y}+\frac{\partial v}{\partial x}\right)\right], \\
F_{T, S}=\frac{\partial}{\partial x} A_{h} \frac{\partial(T, S)}{\partial x}+\frac{\partial}{\partial y} A_{h} \frac{\partial(T, S)}{\partial y} .
\end{gathered}
$$

Where,

$u, v=$ the horizontal components of the velocity vector, $w=$ the vertical component of the velocity vector,

$g=$ the gravitational acceleration,

$p=$ the local pressure,

$\rho(x, y, z, t, T, S)=$ the local density,

$\rho_{o}=$ the reference water density,

$A_{m}=$ the horizontal turbulent diffusion coefficient,

$A_{m v}=$ the vertical turbulent diffusion coefficient,

$f=2 \Omega \sin \theta$ is the Coriolis parameter ( $\theta=$ latitude, $\Omega=$ $7.2921 \times 10^{-5} \mathrm{rad} \mathrm{s}^{-1}$ )

$T=$ the potential temperature,

$S=$ the potential salinity,

$A_{h}, A_{h v}=$ the horizontal and vertical thermal diffusivity coefficients,

$F_{x}, F_{y}=$ the horizontal viscosity

$F_{T}, F_{S}=$ the horizontal diffusion terms of temperature and salinity.

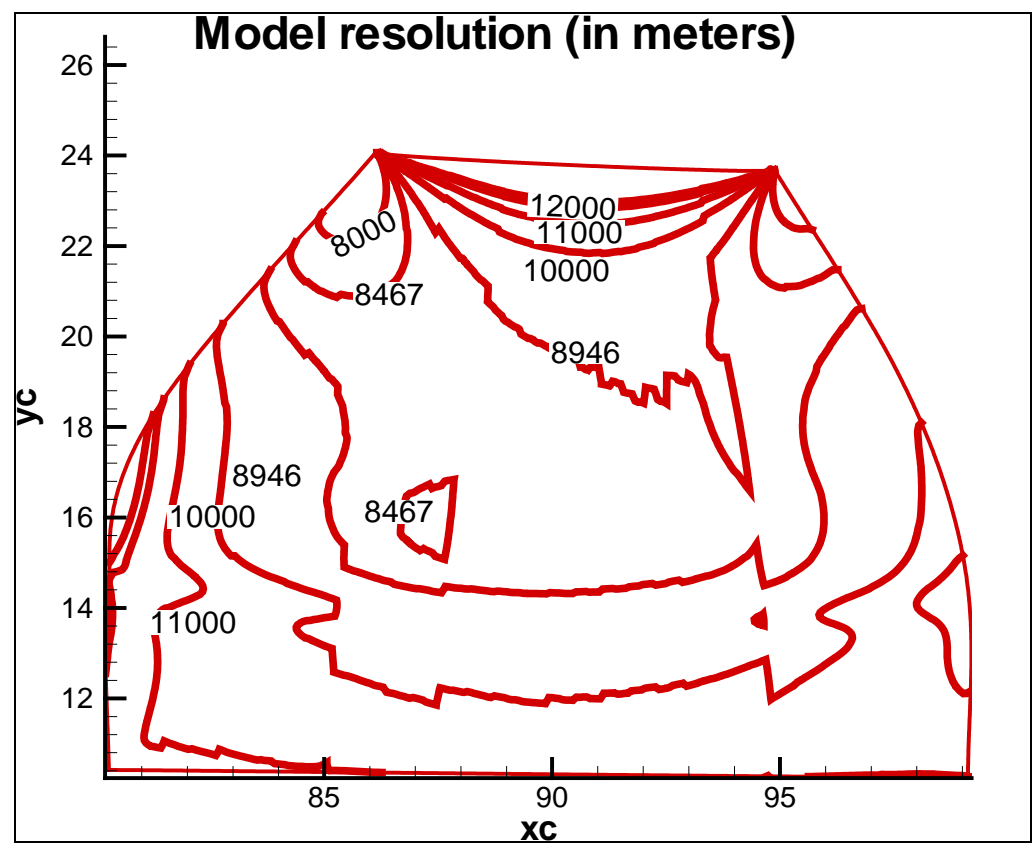

Figure 4. Model resolutions (meters) of the study domain(BOB), $\mathrm{xc}=$ Longitude (Deg. E), yc = Latitude (Deg, N)

The model used in this study extends from $10.0^{0}$ to $25.0^{\circ} \mathrm{N}$ and $80.0^{\circ}$ to $100.0^{\circ} \mathrm{E}$ (Figure1 \& Figure 4) that uses orthogonal curvilinear grid with Arakawa C-grid staggering, with a variable horizontal grid resolution of 4 to $12 \mathrm{Km}$ (Figure 4). The model has 250 x 250 horizontal grid points and 26 sigma layers in the vertical. The model 
uses the bottom topography derived from the Earth Topography and Ocean Bathymetry Database (ETOPO5) at 5-minutes resolution from NGDC database as shown in the Figure 1.The two-dimensional external mode uses a short time-step of $12 \mathrm{sec}$. based on the external wave speed, while a three-dimensional internal mode uses a long time-step of $540 \mathrm{sec}$ based on the internal wave speed. Courant-Fredrick-Levy (CFL) condition has been followed for computational stability.

\begin{tabular}{|c|c|}
\hline \multicolumn{1}{|c}{ Table 1. Model Attributes } \\
\hline Model type/code & Primitive Equations, Free surface/stand alone \\
\hline Vertical grid & $\operatorname{Sigma}(\sigma),(\sigma=\mathrm{Z}-\eta / \mathrm{H}+\eta)$ \\
\hline Horizontal grid & C-grid, curvilinear (orthogonal) \\
\hline Vertical mixing & Mellor Yamada(2.5) \\
\hline Horizontal mixing & Smagorinsky \\
\hline Advection scheme & 2nd order centred \\
\hline Time-stepping & Standard leap-frog \\
\hline Time steps mode & $\begin{array}{c}\text { Split mode: baroclinic/internal \& } \\
\text { barotropic/external }\end{array}$ \\
\hline
\end{tabular}

\subsection{Atmospheric Forcing}

The atmospheric forcing includes wind and heat flux forcing for the BOB application of POM. The wind forcing applied is determined by

$$
\rho_{0} K_{M}\left(\frac{\partial u}{\partial z}, \frac{\partial v}{\partial z}\right)_{z=0}=\left(\tau_{0} x, \tau_{0} y\right)
$$

Where, $K_{M}$ is the vertical mixing coefficient for momentum, and $(u, v)$ and $\left(\tau_{0} x, \tau_{0} y\right)$ are the two components of the water velocity and wind stress vectors, respectively. Surface thermal forcing used in this study is restoring type heat plus salinity flux forcing following in the line of Chu et al.(2000) and is depicted as

$$
\begin{aligned}
& K_{H} \frac{\partial \theta}{\partial z}=\alpha_{1}\left(\frac{Q_{H}}{\rho c_{p}}\right)+\alpha_{2} C\left(\theta_{O B S}-\theta\right), \\
& K_{S} \frac{\partial S}{\partial z}=\alpha_{1} Q_{S}+\alpha_{2} C\left(S_{O B S}-S\right),
\end{aligned}
$$

$Q_{H}=(\mathrm{Qb}+\mathrm{Qsen}+\mathrm{Qlet})=>$ Net heat flux $=($ Net long wave radiation + Sensible heat flux + latent heat flux).

$Q_{S}=\mathrm{S}_{\mathrm{OBS}}(\mathrm{E}-\mathrm{P})=>$ Salinity flux $=$ Sea surface salinity (evaporation rate - precipitation rate)

$\theta_{\mathrm{OBS}}, S_{\mathrm{OBS}}=$ (Sea surface temperature, Sea surface salinity) observed, and

$\theta, S=$ (Sea surface temperature, Sea surface salinity) model.

The parameters $\left(\alpha_{1}, \alpha_{2}\right)$ are $(0,1)$ type switches and $C$ is the relaxation coefficient and, the subscripts 'OBS' represent the observed. $\mathrm{K}_{\mathrm{H}}$ and $\mathrm{K}_{\mathrm{S}}$ are the vertical mixing coefficients for temperature and salinity, respectively. The mixing coefficients $\mathrm{K}_{\mathrm{M}}, \mathrm{K}_{\mathrm{H}}$ and $\mathrm{K}_{\mathrm{S}}$ were computed using level two-turbulence closure scheme (Mellor and Yamada, 1982).

\subsection{Lateral Boundary Forcing}

Closed lateral boundaries, i.e. the modeled ocean bordered by land, were defined using a no slip condition for velocity and a zero gradient condition for temperature and salinity. No advective or diffusive heat, salt or velocity fluxes occur through these boundaries. At open boundaries, the numerical grid ends but the fluid flow is unrestricted. When the water flows into the model domain, temperature and salinity at the open boundary are likewise prescribed from the mean monthly climatology data (Levitus and Boyer, 1994a,1994b). Radiative boundary conditions are prescribed for momentum and thermal variables at the lateral open boundaries when water flows out of the domain (Mellor 2001; Chu et al., 2000), the radiation condition was applied,

$$
\frac{\partial}{\partial t}(\theta, S)+U_{n} \frac{\partial}{\partial n}(\theta, S)=0
$$

Where, the subscript $\mathrm{n}$ is the direction normal to the boundary.

\section{Experiment Design}

The model is initialized with zero initial velocity with 3-dimensional gridded temperature and salinity monthly climatology and realistic bathymetry. Model was forced with QSCAT/NCEP monthly wind stress in order that the model achieved the steady conditions. During the experimental stage it was forced with real time 6-hourly QSCAT/NCEP blended wind field superimposed with synthetic vortex (Carr \& Elsberry, 1997) which provides the realistic cyclonic winds to $\mathrm{BOB}$, and this was termed as experiment I and in experiment II heat plus salinity fluxes have also been included as surface thermal forgings. Model is integrated for 48 hours starting from 06UTC $27^{\text {th }}$ Oct. to 06UTC $29^{\text {th }}$ Oct. 1999. On $29^{\text {th }}$ Oct. at about 06UTC cyclone made land fall, so model run was stopped. The upper ocean thermal features viz. SST, subsurface temperature fields, depth variations of temperature were output by the model. 6-hourly snapshots are stored for daily analysis.

\section{Results and Discussion}

Results yielded from the model simulations due to the TC05B, 1999 on the surface and subsurface thermal features in the upper ocean as ocean's response to TC05B, 1999 are discussed here.

\subsection{Sea Surface and Subsurface Temperature Cooling}

SST is one of the most vital parameters in understanding the air-sea interaction processes, especially during severe weather events (storm). The model produced SST fields [experiments I (wind) and experiment II (wind + heat)] for the $28^{\text {th }}$ Oct. and $29^{\text {th }}$ Oct. due to TC05B, 1999 along with the observed (TMI ) SST for comparison purposes are shown in Figure 5. In the figures the track of the storm is superimposed over the SST plots and different days $\left(25^{\text {th }}\right.$ to $29^{\text {Th }}$ Oct. 1999) are labeled on the track during its life-cycle. Model simulated SST showed pronounced variations in the temperature fields. It could be seen that there is the significant reduction in SST due to the passage of the storm in both 
the experiments during $28^{\text {th }}$ and $29^{\text {th }}$ Oct. 1999. As the storm moved in the northwestwards, the cooler SST, coupled to the storm centre moved along with it, while warmer SST occurred behind it. A noteworthy feature of warming also reflected on the rear end of the storm. Though the maximum cooling in SST occurred beneath the storm centre, it is right asymmetric (biased) and confirms the findings as described in (Nelson 1998; Shay et al., 1993; Chu et al., 2000). Right biased could be attributed to the dominant wind stress (cyclonic winds) to right of the storm track. On $29^{\text {th }}$ Oct. 1999 more drops in SST was reflected compared to the $28^{\text {th }}$ Oct. 1999 , at the same time more cooling was also revealed in experiment
II, compared to the experiment I. It could be noticed that there is the time lag of $\sim 24$ hrs between the storm centre and the centre of maximum cooling. Model simulated SST is well comparable qualitatively with the observed TMI SST imageries (Figure 5). However, TMI imageries show patches of cooling in surface temperature left to the track also near the coastal region of shallow bathymetry. The cooling processes could be attributed to the mixing due to cyclonic wind stress, heat loss from the sea surface (latent and sensible heat fluxes, as shown in Figure 10), upwelling through surface divergence and entrainment mixing at the base of the surface homogeneous layer due to storm.
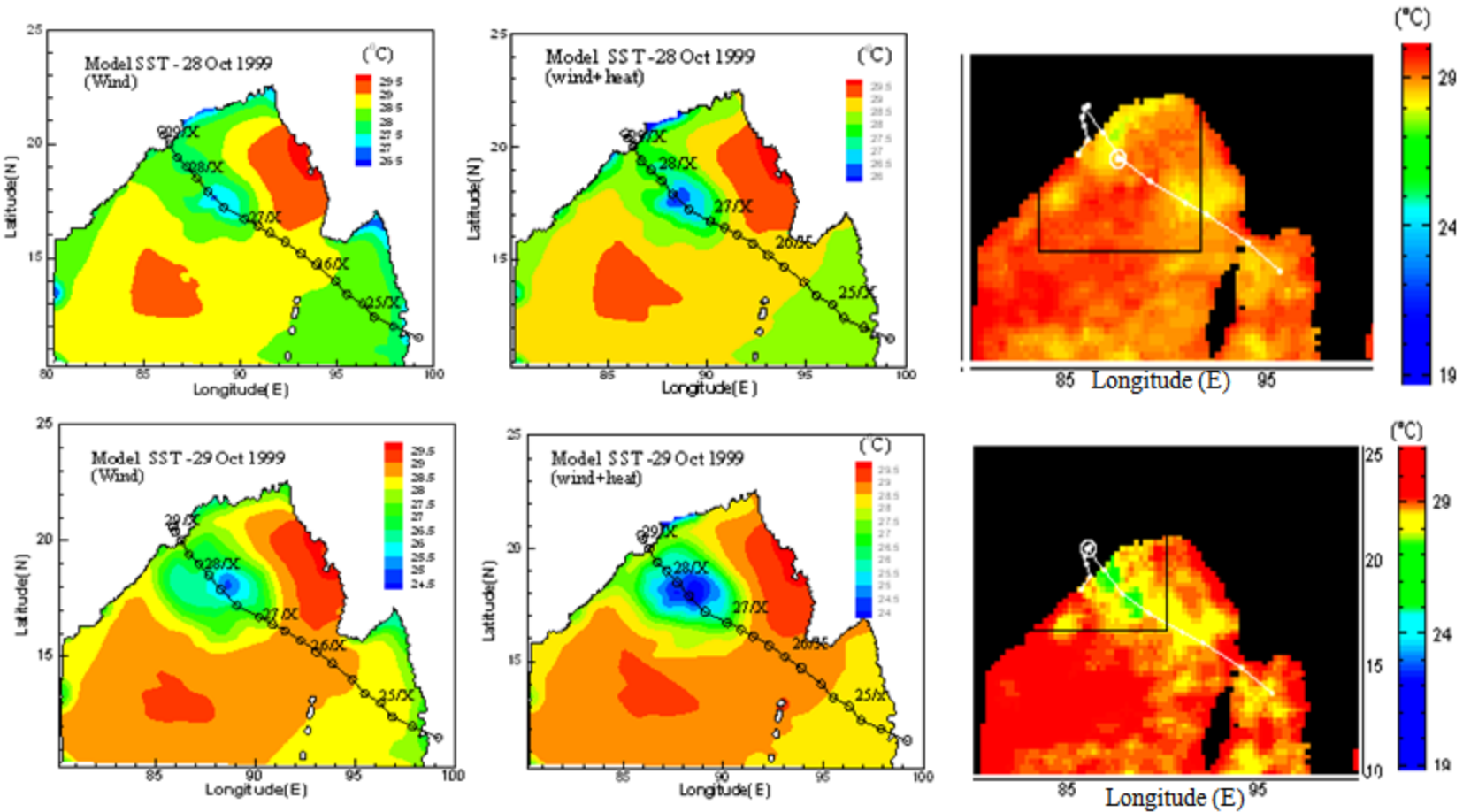

Figure 5. Model SST for $28^{\text {th }}$ Oct. and $29^{\text {th }}$ Oct. 1999 for experiment I (left panel) and experiment II (middle panel) compared with TMT SST (right panel). Tracks of the TC05B 1999 is superimposed and superscribed with different dates (25 to $29^{\text {th }}$ Oct., 1999) on modeled SST maps

The SST plots of 2-days composite (ending on $29^{\text {th }}$ Oct. 1999) of simulated SST are characterized with drop in SST in the wake of the cyclone and are in coherent upto certain extent with the TMI (3- days composite ending on $29^{\text {th }}$ Oct. 1999 , since TMI composite are available 3-day basis) imageries. 3-day composite of TMI imagery show pronounced cooling in the right side of the storm, whereas in model output in both the experiments it observed some warming also to the right of the storm and cooling has followed the storm track and beneath the system more cooling is reflected (Figure 6).
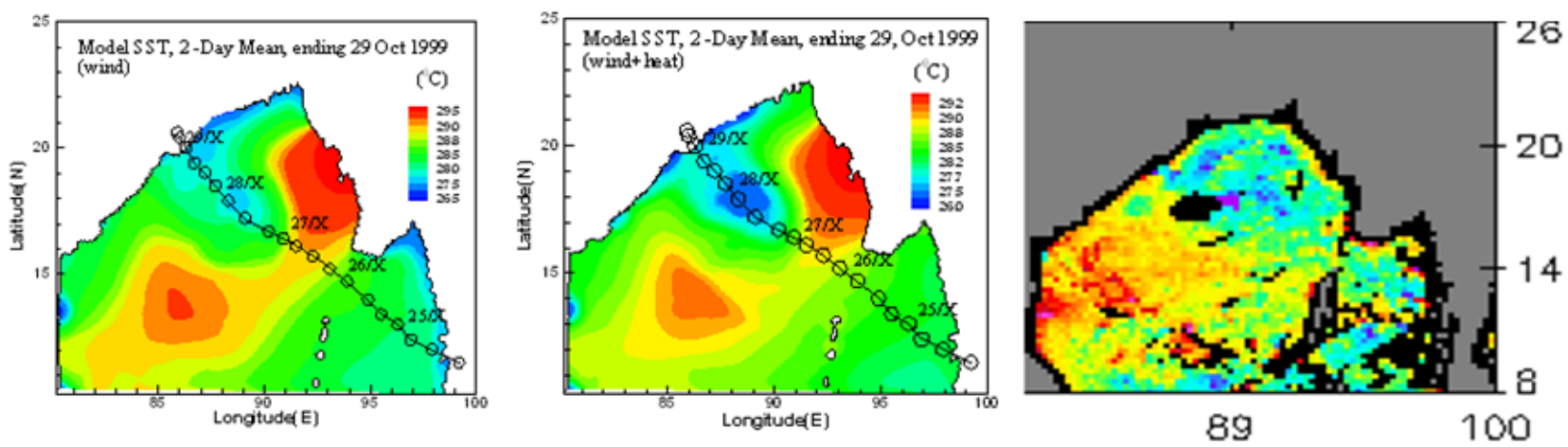

Figure 6. Model SST (2-day composite) for $29^{\text {th }}$ Oct. 1999 for experiment I (left panel) and experiment II (middle panel) compared with TMI SST (3day composite)(right panel). Tracks of the TC05B 1999 is superimposed and superscribed with different dates ( $25^{\text {th }}$ to $29^{\text {th }}$ Oct., 1999) on modeled SST maps

Model simulated SST anomaly showed the striking similarities when compared with TMI SST anomaly
(Figure 7). The higher value of negative SST anomaly along the track is the indicative of the mixing and 
upwelling processes due to the moving storm. The model SST anomaly (model_simulated SST - monthly_Levitus SST $)$ amounting to $\sim\left(-5.0^{\circ} \mathrm{C}\right.$, maximum $)$ is higher than the TMI SST anomaly (OI_TMI SST - Reynolds_climatology
SST) (maximum value is $\sim\left(-3.0^{\circ} \mathrm{C}\right)$ ) for $29^{\text {th }}$ Oct. 1999.This discrepancy in SST anomaly could be attributed to the background SST data used in determining the anomaly culled from different sources.
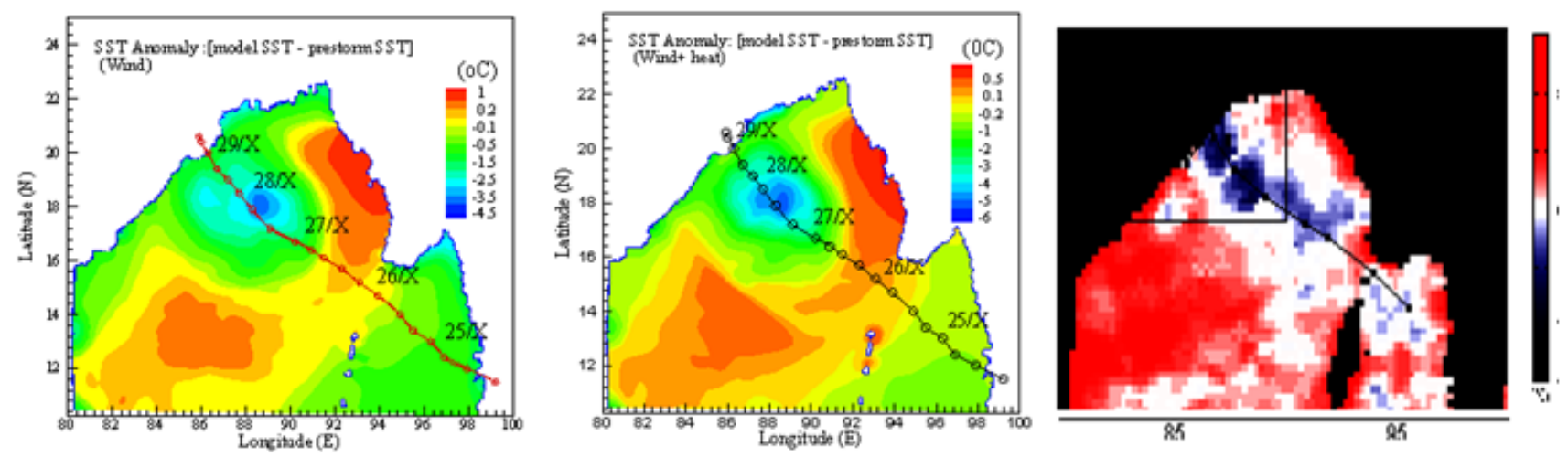

Figure 7. Model SST anomaly for $29^{\text {th }}$ Oct. 1999 for experiment I (left panel) and experiment II (middle panel) compared with TMI SST anomaly (right panel). Tracks of the TC05B 1999 is superimposed and superscribed with different dates (25 $5^{\text {th }}$ to $29^{\text {th }}$ Oct., 1999) on modeled SST maps
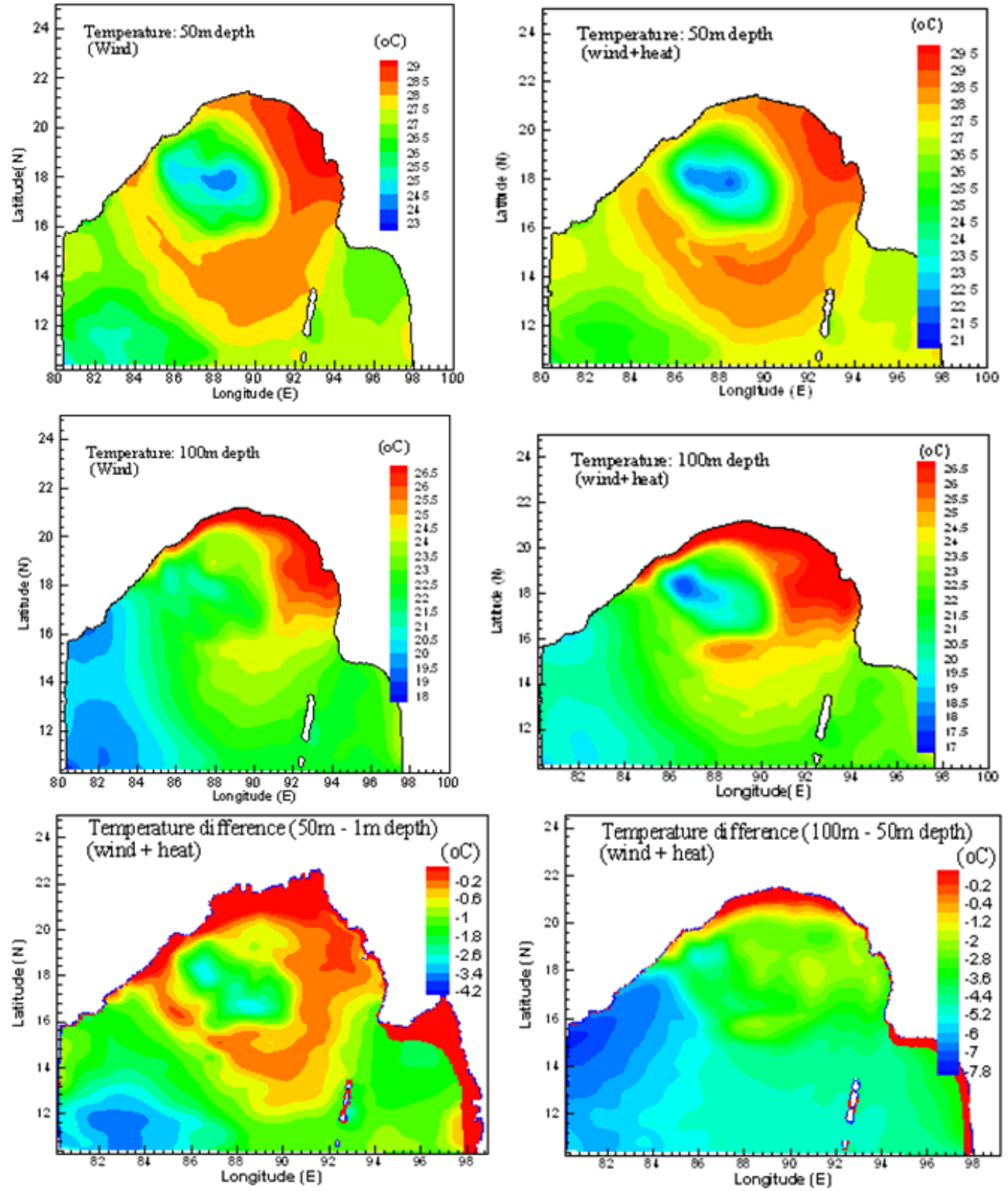

Figure 8. Model subsurface temperature fields for 50m \& $100 \mathrm{~m}$ depths and difference (50m-1m) \& (100m-50m) depths for $29^{\text {th }}$ Oct. 1999 for experiment I (left panel) and experiment II (right panel)

Modeled subsurface temperature fields for $29^{\text {th }}$ Oct. 1999 for both the experiments I and II, for $50 \mathrm{~m}$ and $100 \mathrm{~m}$ depths respectively are shown in the Figure 8. It is obvious from the figures that storm impact in reducing the 
horizontal temperature distribution is significant at different depths. As the storm moved over surface waters its influence in reducing the temperature at the subsurface depths beneath the storm centre is noticed clearly in both the experiments. Cooling in subsurface temperature fields is more pronounced in experiment II, when the thermal forcing was also applied as compared to experiment I. However, storms impact on subsurface temperature field away from its centre is less pronounced.

The difference in temperature fields between the subsurface $(50 \mathrm{~m})$ and surface (1m) (i.e., 50m - SST(1m)) and $100 \mathrm{~m}$ and $50 \mathrm{~m}$ (i.e., $100 \mathrm{~m}-50 \mathrm{~m}$ ) depths, respectively for both the experiments for $28^{\text {th }}$ and $29^{\text {th }}$ Oct., 1999 are also illustrated (Figure 8). It could be seen that there is the marked variation in temperature fields. These differences came out to be about $4.0^{\circ}$ (Maximum) for the depth difference of $(1 \mathrm{~m}-50 \mathrm{~m})$ and $3 \cdot 0^{\circ}$. (Maximum) for depth difference of $(100 \mathrm{~m}-50 \mathrm{~m})$, respectively indicating the diminishing impact of storm on subsurface temperature fields as depth increases. It could also be observed that at the surface (1m depth) values of temperature is higher as compared to the $50 \mathrm{~m}$ and $100 \mathrm{~m}$ depths. Similarly, temperature fields at $50 \mathrm{~m}$ depths are higher as compared to $100 \mathrm{~m}$ depths. Bias in temperature cooling even at the subsurface depths could also be noticed in both the experiments.

Superimposed exhibit between the simulated SST and surface current for the experiment II (29 ${ }^{\text {th }}$ Oct., 1999) are illustrated in Figure 9. It could be noticed that SST
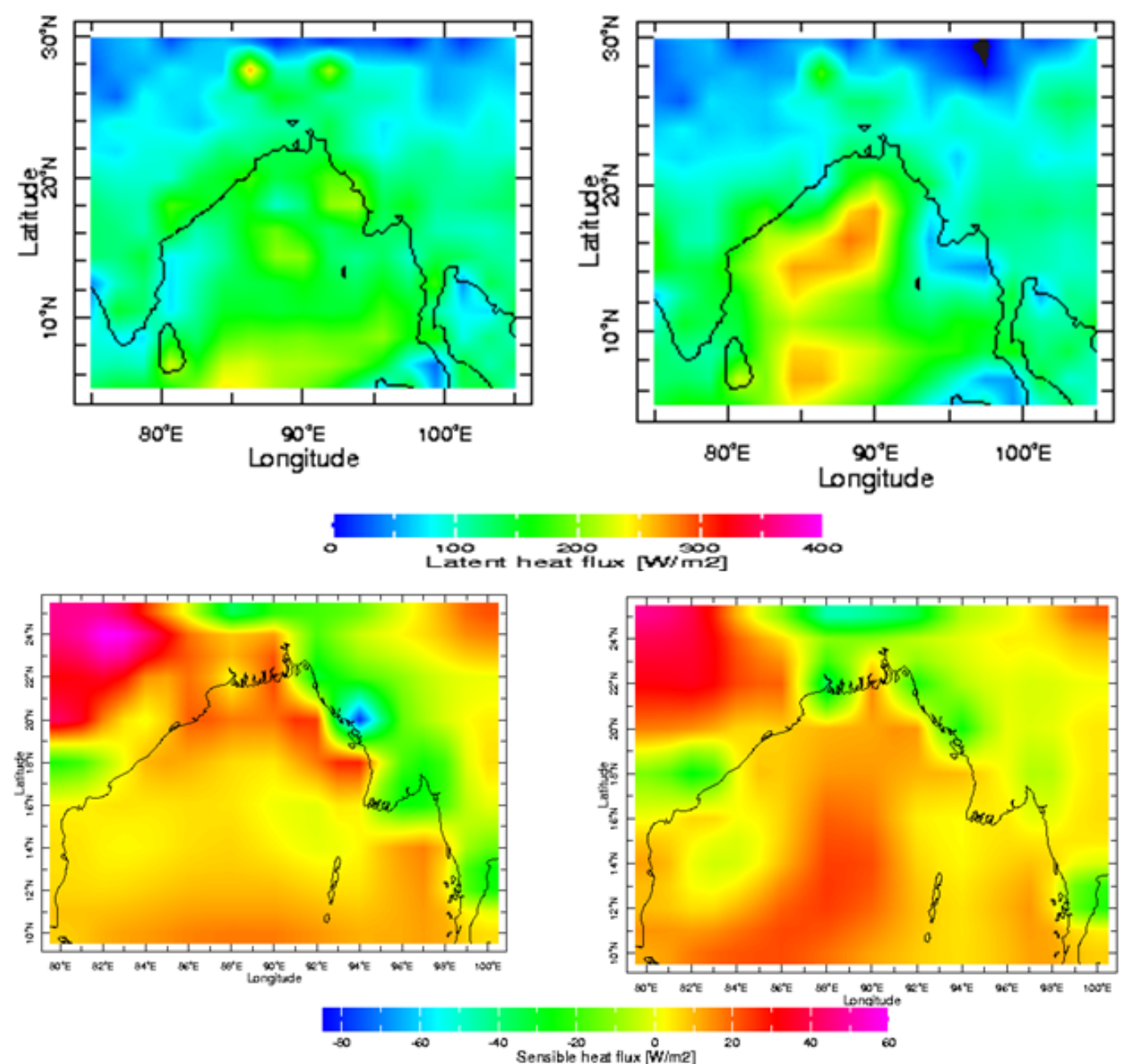

Figure 10. Latent heat flux (upper row) and sensible heat flux (lower row) on 28th Oct. 1999 (Left panel) and $29^{\text {th }}$ Oct.1999 (right panel)

cooling has followed the pattern of wind stress due to storm and surface current show surface divergence. Maximum values of current vector (arrows) are in the order of about $3.5 \mathrm{~ms}^{-1}$ and current are representing the surface divergence flow and SST cooling through upwelling.

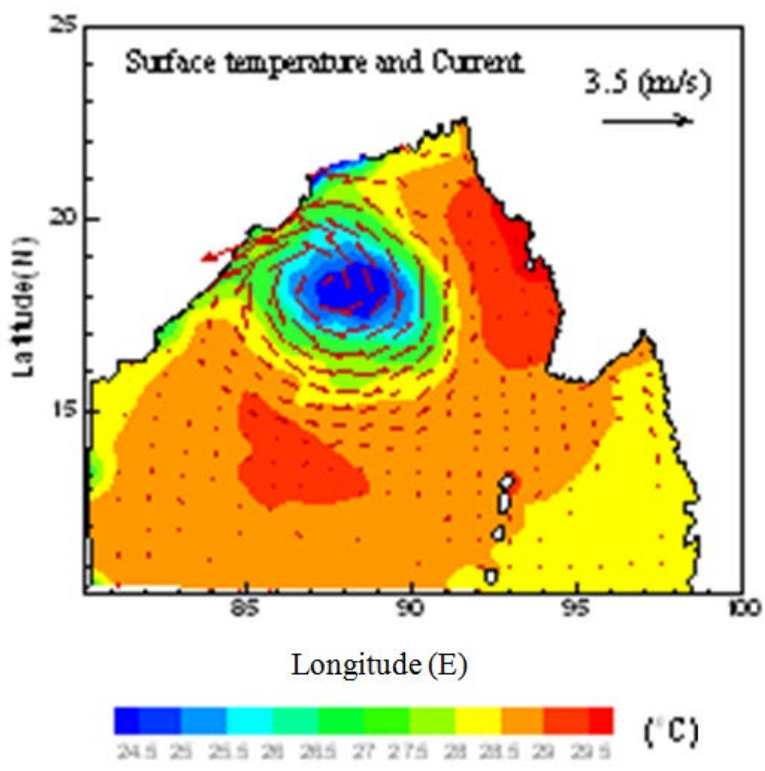

Figure 9. Model SST superimposed with model surface current for $29^{\text {th }}$ Oct. 1999 for experiment II

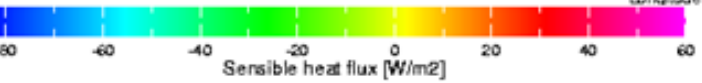


However, the preliminary results presented in this study may prove more convincing through the comparative study of model simulations of the thermal response of the upper ocean by taking the case of CAT 5 equivalent cyclone, other than TC05B, 1999 ( Super cyclone, CAT 5). Since TC05B, 1999 was the unique system in terms of its size, intensity (damage potential) and impact in the oceanic environment (open as well as shallow continental shelf region) of Bay of Bengal (Indian Ocean). Moreover, sensitivity study of the thermal response of the upper ocean due to heat plus salinity flux along with momentum forcing (wind stress) and wind stress alone (only) is carried out as experiment I and experiment II, respectively and results are presented. Sensitivity to models low vs. high resolution grids, the choice of diffusion and viscosity, and model initialization through data assimilation using observed (Argo floats, buoy, ships, satellite/radar etc.) data may reproduce more realistic observed features.

\section{Conclusions}

This study used POM to investigate the oceanic thermal response associated with the TC05B, 1999 during postmonsoon season, when the storm was in its higher intensity over ocean during 27 to 29 the Oct. 1999. POM was forced with the wind and heat plus salinity flux forgings. Tropical cyclone wind model generated synthetic winds are superimposed with the satellite and reanalysis derived (QSCAT/NCEP) blended wind fields in order to force the model with reasonable and realistic cyclonic winds. Model simulated SST show maximum cooling beneath the storm, however right bias could also be noticed which confirms the earlier findings. Vigorous cooling occurs where the existing upper ocean homogeneous layer is shallow within a cyclonic eddy. The rapid reduction of SST due to upwelling is dominantly responsible for cooling the upper ocean near the storm center. Model SST cooling are in reasonable agreement with the TMI imageries qualitatively. SST anomaly show appropriate matching with the TMI imageries.

Subsurface temperature differences and cooling patterns are indicative of the storm effect upto the depth of $100 \mathrm{~m}$. Surface current superimposed with SST also show the divergence current beneath the storm centre and maximum cooling due to the divergence of surface water and upwelling of subsurface cooler waters. These highly divergent upper layer currents also generated the typical bias of maximum SST cooling to the right of the storm track.

The comparison of the 2-day modeled mean SST with 3-Day TMI SST (due to unavailability of the 2-day mean in TMI data source) are the limitations of the study. The case of Super cyclone equivalent as comparative study may be taken or case of similar studies may be illustrated for more confirmation of the results. The adoption of data assimilation techniques and quantitative verification of the tropical cyclone wind model may improve the model output. Similarly, modeling studies with good initialization and finer resolution using coupled model will be useful in detailed investigation of oceanic response to storm over North Indian Ocean.

\section{Acknowledgement}

Partial research grant (No.SR/FTP/ES-019/2003) from Ministry of Science and Technology, Government of India as SERC_FTYS program (CAS, IIT Delhi) is kindly acknowledged. Thanks are gratefully acknowledged to Atmospheric and Oceanic Sciences Program of Princeton University, the Geophysical Fluid Dynamics Laboratory of NOAA and Dynalysis of Princeton for Princeton Ocean Model (POM). Data sources QSCAT/NCEP, COADS, Levitus, NGDC are thankfully acknowledged. TRMM TMI data and images are produced by Remote Sensing Systems and supported by NASA's Earth Science Information Partnership (ESIP): A federation of information site for Earth' Science; and by TRMM science team. The editor and the anonymous reviewer are thankfully acknowledged for their constructive comments for the final version of the manuscript.

\section{References}

[1] ANONYMOUS (1979): Tracks of Storms and Depressions in the Bay of Bengal and the Arabian Sea 1877-1970, India Meteorological Department, New Delhi, Charts 1-186.

[2] Chinthalu, G.R., Seetaramayya, P., Ravindran, M., and Mahajan, P.N. (2001): Response of the Bay of Bengal to Gopalpur and Paradip Super Cyclone during 15-31 October, 1999,Curr Sci, 81 (5),283-291.

[3] Gopalakrishna, V.V., Murty, V.S.N., Sarma, M.S.S., and Sastry, J.S. (1993): Thermal Response of Upper Layers of Bay of Bengal to Forcing of a Severe Cyclonic Storm: A case Study, Indian J. Mar. Sci, 22, 8-11.

[4] Kara, A.B., Rochford, P.A., and Hurlburt, H.E. (2000): An Optimal Definition of Ocean Mixed Layer Depth, J. Geophysics Res. 105, 16,803-16,821.

[5] Kara, A.B., Rochford, P.A., and Hurlburt, H.E. (2003a): Mixed Layer Depth Variability Over the Global Ocean, J. Geophysics Res. 108.

[6] Kara, A.B., Rochford, P.A., and Hurlburt, H.E. (2003b): Climatological SST and MLD Prediction from a Global Layered Ocean Model with an Embedded Mixed Layer, J. Atmos. Oceanic Technol, 20, 1616-1632.

[7] Levitus, S. and Boyer, T.P. (1994a): World Ocean atlas 1994,Vol, 4, Temperature, NOAA Atlas, NESDIS, Vol, 4, U.S. Department of Commerce, Washington D.C., U.S.A. pp 1-117.

[8] Levitus, S., Burgett, R., and Boyer, T.P. (1994b): World Ocean atlas 1994, Vol, 3, Salinity, NOAA Atlas, NESDIS, Vol, 4, U.S. Department of Commerce, Washington D.C., U.S.A. pp 1-99.

[9] Rao, Y.R. (2002): The Bay of Bengal tropical cyclones, Curr Sci., 82, 379-381.

[10] Rao, R.R. (1987): Further analysis on the thermal response of the Upper Bay of Bengal to the forcing of pre-monsoon cyclonic storm and summer monsoonal onset during MONEX-79, Mausam, 38 147-156.

[11] Shay, L.K., (1994): Oceanic Response to tropical cyclones. In the Oceans: Physical-Chemical Dynamics and Human Impact (eds. S.K. Mujumdar, E.W. Miller, G.S. Forbes, R.F. Schmalz, and Assad A. Panah) (The Pennsylvania Academy of Science), pp. 1497.

[12] Shay, L.K., Goni, G. J., and Black, P.G. (2000): Effects of Warm Oceanic Feature on Hurricane Opal, Mon. Weath. Rev., 128, 1367-1383.

[13] Price, J.F. (1981): Upper ocean response to a hurricane, J. Physics. Oceanogr., 11,153-175.

[14] Mellor, G.L. (2001): One-dimensional, ocean surface layer modeling, a problem and a solution, J. Physc. Oceanogr., 31, 790809.

[15] Mellor, G.L. and T. Yamada (1982): Development of a turbulence closure model for geophysical fluid problems, Rev. Geophys., 20, 851-875.

[16] Zedler, S.E., Dickey, T.D., Doney, S.C., Price,J.F., Yu, X., and Mellor, G.L (2002):Analysis and simulations of the upper ocean's response to Hurricane Felix at the Bermuda Testbed Mooring site: 13-23 August 1995, Vol. 107, NO, C12, 3232. 
[17] Jacob, S.D. and Shay, L.K (2003): The role of oceanic mesoscale features on the tropical cyclone-induced mixed layer response: A case study, 649-676.

[18] Vinaychandran, P. N., Murty, V.S.N. and Ramesh Babu, V. (2002): Observations of barrier layer formation in the Bay of Bengal during Southwest Monsoon, J. Geophy. Res., 107, 8018.

[19] Subramanyam, B., et al. (2005): Air-sea coupling during the tropical cyclone in the Indian Ocean: A case study using satellite observations, Pure and Applied Geophys., 162, 1643-1672.

[20] Sadhuram, Y. (2004): Record decrease of sea surface temperature following the passage of super cyclone over the Bay of Bengal, Current Sci., 86(3), 383-384.

[21] Gray, W.M. (1979):In Meteorology over Tropical Oceans (ed. Shaw,D.B.),R. Meteorol. Soc., Bracknell, pp. 155-218.

[22] Leipper, D.F.(1967): Observed ocean conditions and hurricane Hilda, 1964, J. Atmos. Sci., 24,182-196.

[23] Lin, I.-I., Liu, W.T., Wu, C.-C., Chiang, J.C.H., and Sui, C.-H. (2003): Satellite observations of modulation of surface winds by typhoon-induced upper ocean cooling,Geophys. Res. Lett., 30, 1131.

[24] Nelson, N. B. (1998): Spatial and temporal extent of sea surface temperature modifications by hurricanes in the Sargaso Sea during the 1995 season, Mon. Wea. Rev., 126, 1364-1368.

[25] Stramma, L., Cornillion, P. and Price, J.F. (1986): Satellite observation of sea surface cooling by hurricanes, J. Geophys. Res., 91, 5031-5035.

[26] Wright, R. (1969): Temperature structure across the Kuroshio before and after typhoon Shirley, Tellus, 21,409-413.

[27] Chu, P.C., Veneziano, J.M., and Fan C. (2000): Response of the south China sea to tropical cyclone Ernie 1996, 105(C6), 13, 99114009.

[28] Carr, L.E., III and Elsberry, R.L. (1997): Models of Tropical cyclone wind distribution and beta-effect propagation for application to tropical cyclone track forecasting, Mon. Wea. Rev. 125, 3190-3209.

[29] Wentz, F.J., Gentemann, C., Smith, D., and Chelton, D.(2000): Satellite measurements of sea surface temperature through clouds, Science, 288, 847-850.

[30] Maeda, A., (1964): On the Variation of the Vertical Thermal Structure, J. Oceanogr. Soc. Japan, 20(6), 255-263.

[31] Mohanty, U.C., Mandal, M., Raman, S. (2004): Simulation of Orissa Super Cyclone 1999 using PSU/NCAR Mesoscale Model, Natural Hazards, 31, 373-390.

[32] Blumberg, A. F., and Mellor, G. L. (1987): A description of a three-dimensional coastal ocean circulation model. ThreeDimensional Coastal Ocean Models. Vol. 4, N. Heaps, Ed., American Geophysical Union. 208 pp.

[33] Morey S.L., Bourasa M.A., Dukhovskoy D.S., O’Brian J.J. (2006) Modeling studies of the upper ocean response to a tropical cyclone, Ocean Dynamics.

[34] Liu H., Liu B., Xie L., and Zhang K. (2012): Simulation Of Ocean Responses To An Idealized Landfalling Tropical Cyclone Using A Coupled Atmosphere-Wave-Ocean Modeling System, Tropical Cyclone Research and Review, 1(3), 373-389.

[35] Greatbatch, R.J. (1985): On the role played by upwelling of water in lowering sea surface temperatures during the passage of a storm. Journal of Geophysical Research 90.

[36] Dickey, T. D., Frye, D., Mcneil, J., Manov, D., Nelson, N., Sigurdson, D., Jannasch, H., Siegel, D., Michaels, A. F., and Johnson, R. J. (1988): Upper-ocean temperature response to Hurricane Felix as measured by the Bermuda Testbed Mooring, Mon. Weather Rev., 126, 1195-1201.

[37] Cornillon, P., Stramma, L., and Price, J. F. (1987): Satellite measurements of sea surface cooling during hurricane Gloria, Nature, 326, 373-375. 